\title{
FORMULATION AND EVALUATION OF COSMETIC FOUNDATION USING EPIGALLOCATECHIN GALLATE AS A SUN PROTECTION
}

\author{
EFFIONORA ANWAR*, SHIFA RIZKAMIARTY
}

Laboratory of Pharmaceutics and Pharmaceutical Technology Development, Faculty of Pharmacy, Universitas Indonesia, Depok 16424, West Java, Indonesia. Email: effi.nora@gmail.com

Received: 26 September 2019, Received and Accepted: 17 December 2019

\section{ABSTRACT}

Objective: The objective of the study was to obtain a lotion foundation using epigallocatechin gallate (EGCG) as an active ingredient designed with a sun protection factor (SPF) value around 30 that can effectively protect facial skin from ultraviolet radiation (UVR) exposure and that is safe to use.

Methods: In this study, we determine SPF value using UV-visible spectrophotometry at a wavelength between 290 and 320 nm. The preparation formula of the foundation was made with an EGCG concentration of $0.4 \%$, a concentration which can yield the desired SPF value of about 30 . Physical stability was performed at low $\left(4 \pm 2^{\circ} \mathrm{C}\right)$, ambient $\left(25 \pm 2^{\circ} \mathrm{C}\right)$, and high $\left(40 \pm 2^{\circ} \mathrm{C}\right)$ temperatures; cycling and centrifugation tests were also conducted. Safety was evaluated by eye irritation test using hen's egg test on chorioallantois method and skin irritation test using the Draize and patch tests method.

Results: The SPF values of $0.04 \%$ EGCG and lotion foundation containing $0.4 \%$ EGCG were $31.02 \pm 0.72$ and $33.20 \pm 0.59$, respectively. The results of cycling and centrifugal tests indicated that lotion foundation showed an absence of crystals and lack of any phase separation between oil and water phases. The physical stability test showed no significant changes for all parameters. Safety tests resulted in neither skin nor eye irritation.

Conclusion: The EGCG foundation developed was physically stable with a good appearance and did not irritate the skin or eyes thus are safe to use also can effectively protect skin against UVR exposure.

Keywords: Epigallocatechin gallate, Foundation, Irritation test, Sun protection factor.

(C) 2020 The Authors. Published by Innovare Academic Sciences Pvt Ltd. This is an open access article under the CC BY license (http://creativecommons. org/licenses/by/4. 0/) DOI: http://dx.doi.org/10.22159/ijap.2020.v12s1.FF029

\section{INTRODUCTION}

Cosmetics have become a daily necessity within society, resulting in a wide market with high demand. Cosmetics can be classified for skin or body care or as decorative. Decorative cosmetics are used for application and coverage of skin defects, resulting in improved appearance as well as psychological effects such as increased self-confidence. One form of decorative cosmetics is foundation, which serves to cover uneven facial skin surfaces, scars, acne, and pores. Foundation is often equipped with sun protection factor (SPF) serving as a second layer of protection from ultraviolet (UV) rays on the face.

Skin contains its own natural protective system against the effects of sunlight, but this is often ineffective to withstand excessive sun exposure; therefore, additional shielding may be required to protect against UV light [1,2]. Foundation usually contains broad-spectrum physical and chemical sunscreens such as titanium dioxide, zinc oxide, octyl methoxycinnamate, or oxybenzone - to prevent UV radiation (UVR) exposure. However, these components have been reported to cause skin irritation, photosensitivity, and contact dermatitis by interaction with cutaneous molecules on chronic use [3]. Therefore, natural compounds such as polyphenols may be more optimal photo protectants.

Flavonoids as antioxidants with strong activities can bind metal ions and prevent the harmful effects resulting from exposure to UV rays [4]. Phenolic compounds, especially flavonoid groups, have potential as sunscreens as the chromophores can absorb UV rays, thereby reducing intensity on the skin. One compound that can be used for these purposes is epigallocatechin gallate (EGCG).

EGCG is an effective antioxidant primarily found within green tea leaves, in which its content can protect the skin from UVR. The SPF value of $200 \mu \mathrm{g} / \mathrm{mL}$ green tea leaf extract measured in vitro using a UV-visible spectrophotometer was $18.10 \pm 0.05$ [5]. Elevated SPF values can be caused by high levels of polyphenols and flavonoids in green tea. The high antioxidant activity of EGCG as a sunscreen could be beneficial for skin health, especially of the face. Nevertheless, there remains no research concerning EGCG SPF values and its use in cosmetics, especially foundation. This encourages research investigating whether EGCG can help counteract UV light when formulated into a foundation serving as makeup and be effective in preventing exposure to UVR.

\section{MATERIALS AND METHODS}

\section{Materials}

EGCG (Sigma Aldrich, Singapore), ethanol pro analysis (Merck, Germany), stearic acid, cetyl alcohol, propylparaben, methylparaben, propylene glycol, polysorbate 80 , sorbitan monooleate, paraffin liquid, xanthan gum, and dimethicone (Brataco, Indonesia), micropore tape (Nexcare $3 \mathrm{M}$ ), distilled water, sterile gauze, brown cosmetic pigment (Dandelion Cosmetics, Indonesia), and hen's eggs were used in this study. Animal tests used three albino rabbits of a New Zealand strain with weights $>2 \mathrm{~kg}$, which were obtained from a rabbit breeder in the Bogor area (West Java, Indonesia).

\section{Methods}

EGCG SPF value analysis

Determination of sunscreen effectiveness was performed by determining the SPF value through UV-visible spectrophotometer. EGCG samples of $10 \mathrm{mg}$ were dissolved in $25 \mathrm{~mL}$ of homogeneous ethanol. Absorption curve tests were conducted at a wavelength of $290-320 \mathrm{~nm}$, then set to an absorption of $5 \mathrm{~nm}$ intervals with three repetitions [6]. The EE $\times$ I value was constant, as determined by Sayre et al., 1979. The data obtained were processed using the Mansur equation. 


\section{Foundation formulation}

Foundation was formulated in the form of lotion. Preparation formula of lotion foundation was made with an EGCG concentration of $0.4 \%$, at which concentration the desired SPF value about 30 could be obtained. The lotion formulated in this study was made with reference to Duma research with some modifications, as can be seen in Table 1 [7].

Preparation of foundation lotion was carried out by mixing the pharmaceutical oil compound and cosmetic pigment ingredients, which were melted over a water bath until reaching $70^{\circ} \mathrm{C}$. Liquid phase materials were prepared by dissolving material into water at a temperature of $70^{\circ} \mathrm{C}$, then propylene glycol was added while maintaining the temperature. Oil phase was added piecemeal continuously into the liquid phase material while stirring with a homogenizer at a constant rate of $1500 \mathrm{rpm}$ for $30 \mathrm{~min}$. The mixing results were continued with stirring until viscous liquids were formed. Furthermore, EGCG was gradually added with stirring to obtain a homogenous mixture when conditions reached room temperature $\left(25-30^{\circ} \mathrm{C}\right)[7,8]$.

\section{Foundation evaluation}

The evaluation included organoleptic, homogeneity, $\mathrm{pH}$, globule diameter, viscosity, and flow properties, as well as physical stability tests.

\section{SPF value analysis of EGCG foundation}

The determination of sunscreen effectiveness was performed by determining the SPF value through UV-visible spectrophotometer. One gram of foundation sample was dissolved in ethanol up to $10 \mathrm{~mL}$ until reaching homogeneity, then vigorously shaken and vortexed for approximately $15 \mathrm{~min}$ so that active EGCG substances were dissolved. The mixture was centrifuged for $15 \mathrm{~min}$ at $3000 \mathrm{rpm}$ for phase separation, and the supernatant (top phase) was collected. The test absorbent curve was used at wavelengths of $290-320 \mathrm{~nm}$, then the same calculations were performed for the determination of SPF EGCG value.

\section{Rabbit skin irritation test}

Skin irritation test was performed using three albino New Zealand strain rabbits with weights of $>2 \mathrm{~kg}$. Before use, the rabbits were acclimatized for 3 days. One day before the experiment, the back of the animals was shaved with a razor and depilatory cream; two test areas on the rabbit ridges were further prepared and clean shaven. In each test area, a test preparation was applied with $500 \mathrm{mg}$ of foundation. Subsequently, the test areas were covered with sterile gauze and bandaged with non-irritant plaster. After setting for $4 \mathrm{~h}$, the patch was opened and test preparation residue was immediately removed using water. Tests were evaluated whether erythema and edema occurred after the patch was opened; assessment of responses was performed

Table 1: Formula of EGCG foundation lotion

\begin{tabular}{|c|c|}
\hline Ingredients & Total $(\% \mathrm{~b} / \mathrm{b})$ \\
\hline EGCG & 0.4 \\
\hline \multicolumn{2}{|l|}{ Oil phase } \\
\hline Stearic acid & 2 \\
\hline Cetyl alcohol & 4 \\
\hline Paraffin liquid & 20 \\
\hline Span 80 & 1.35 \\
\hline Propylparaben & 0.02 \\
\hline Dimethicone & 5 \\
\hline Brown pigment & 0.05 \\
\hline \multicolumn{2}{|l|}{ Liquid Phase } \\
\hline Tween 80 & 3.65 \\
\hline Methylparaben & 0.18 \\
\hline Propylene & 5 \\
\hline glycol & \\
\hline Xanthan gum & 0.3 \\
\hline Distilled water & Ad 100 \\
\hline
\end{tabular}

by expert veterinarians after opening of the patches after 24,48 , and $72 \mathrm{~h}$. The assessment category of test resulting in skin reactions was subsequently determined based on the International Standard ISO 10993-10 established in 2002.

\section{Skin irritation test patch test method}

Irritation tests were done by repeated opened patch test (ROPT) on volunteers. Results were recorded at $1,24,48$, and $72 \mathrm{~h}$ after $0.1 \mathrm{~g}$ was applied to skin of the upper back of $3 \mathrm{~cm}$ in diameter, as well as a control dosage. Volunteers were instructed not to wash this area of skin during the test. Skin reactions were evaluated after 24,48 , and $72 \mathrm{~h}$ and reactions were observed by experts.

\section{Eye irritation test}

Eye irritation test was performed using hen's egg test on chorioallantois method (CAM), a test method of mucous membrane safety (e.g., for eye irritation) without animal use [9]. This test used 12 pieces of leghorn fertile hen's eggs. The reaction occurring within $300 \mathrm{~s}$ was observed and the results with time of occurren

ce in seconds were recorded. Reactions potentially arising included: Bleeding (hemorrhage), lysis of blood vessels (hyperemia), and coagulation (denaturation of intra- and extravascular proteins) [10]. Analyses were performed using irritation score (IS) calculations.

\section{RESULTS AND DISCUSSION}

The SPF value of EGCG at a concentration of $400 \mu \mathrm{g} / \mathrm{mL}$ was $31.02 \pm 0.72$. Results of SPF EGCG values at concentrations of 100, 150, 250, and $400 \mu \mathrm{g} / \mathrm{mL}$ are shown in Fig. 1.

Physical evaluation of the preparations performed includes organoleptic evaluation, homogeneity, $\mathrm{pH}$ measurement, globule size, determination of viscosity, and flow properties (Table 2).

EGCG lotion foundation consisted of a beige color was odorless and homogeneous, $\mathrm{pH} 5.72$, with a globule size diameter of $3.135 \mu \mathrm{m}$, and its viscosity at $5 \mathrm{rpm}$ measured $6300 \mathrm{cps}$. Up to $19 \% \pm 0.22$ of test subjects "really like" the product, $55 \% \pm 0.21$ "like" the product, $22 \% \pm 0.22$ assess the product "to be sufficient", and only $5 \% \pm 0.06$ "dislike" the test

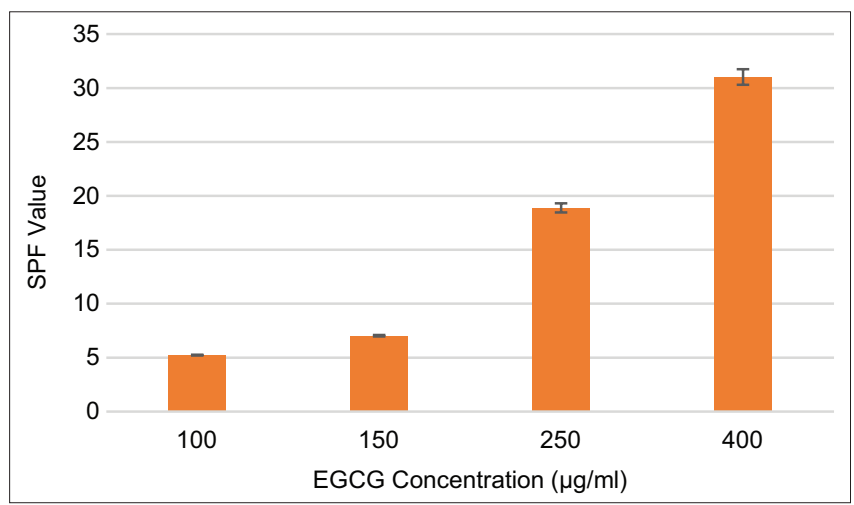

Fig. 1: Graph of epigallocatechin gallate sun protection factor value at concentrations of $100,150,250$, and $400 \mu \mathrm{g} / \mathrm{mL}$

Table 2: Foundation evaluation results

\begin{tabular}{ll}
\hline Physical parameters & Result \\
\hline Color & Beige \\
Odor & Odorless \\
Homogeneity & Homogeneous \\
pH & 5.72 \\
Globule size diameter & $3.135 \mu \mathrm{m}$ \\
Viscosity $(5 \mathrm{rpm})$ & $6300 \mathrm{cps}$ \\
\hline
\end{tabular}


product. According to the overall assessment parameters as given by the panelists, Fig. 2 shows that the EGCG foundation had an attractive physical appearance that was favored by the subjects.

The viscosity exhibited plastic thixotropic flow as can be seen on the rheogram (Fig. 3). The results of the cycling test indicated that the EGCG foundation was stable in that phase separation did not occur between the oil and the water phases and there was an absence of crystals. This observation was performed after six cycles ranging between $4 \pm 2^{\circ} \mathrm{C}$ and $40 \pm 2^{\circ} \mathrm{C}$. These observational results are shown in Fig. 4. Mechanical test results did not show any phase separation between the oil and water phases (Fig. 5).

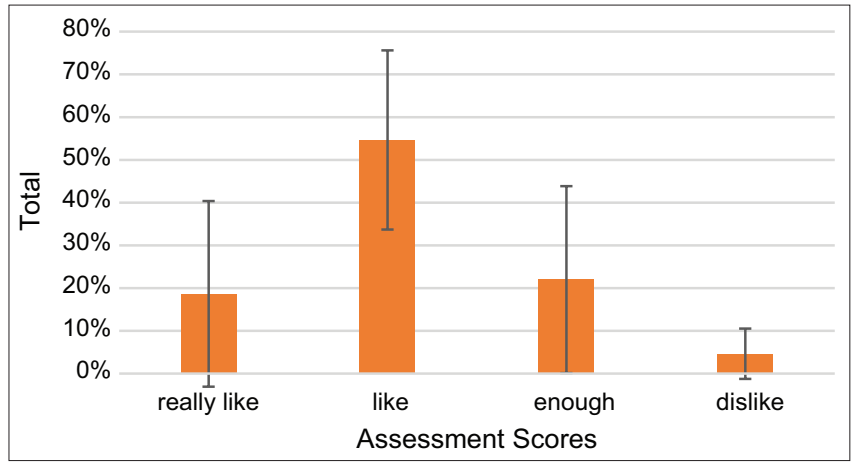

Fig. 2: Diagram of overall result assessment

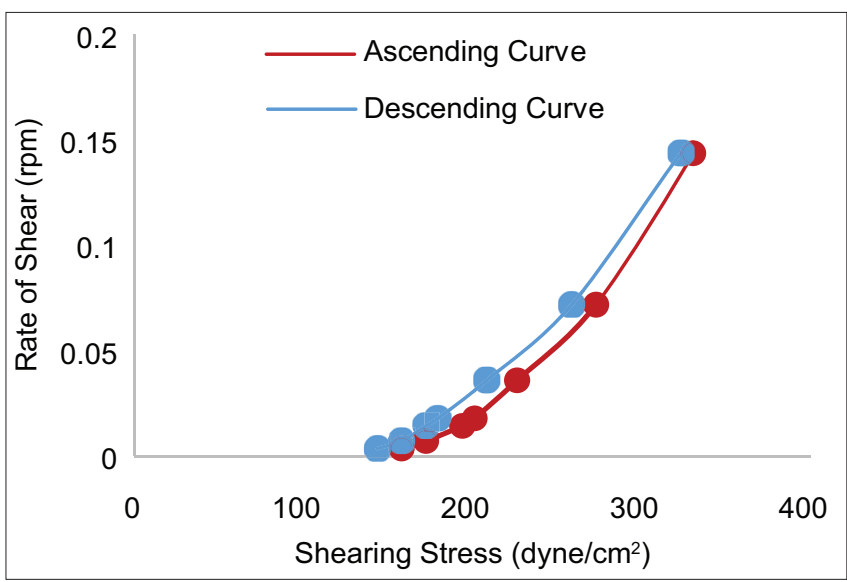

Fig. 3: Rheogram viscosity

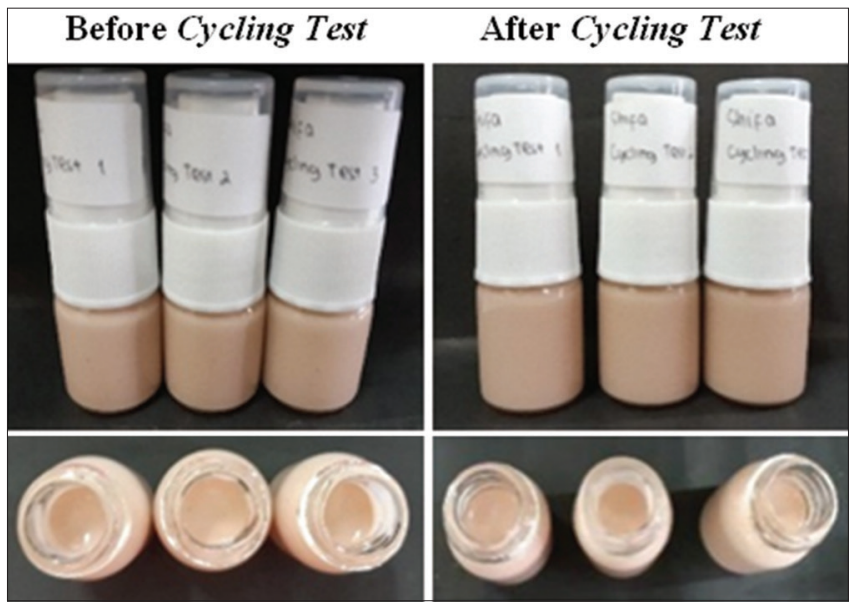

Fig. 4: Cycling test results
Measurement of pH within the 8-week physical stability test showed a change in $\mathrm{pH}$, but this value remained in the $\mathrm{pH}$ range of the skin of 4.5-6.5 (Fig. 6)

Average globule diameter measurements of EGCG foundation lotion at ambient, low, and high temperatures throughout 8 weeks were $4.62 \mu \mathrm{m}$; $3.05 \mu \mathrm{m}$; and $4.60 \mu \mathrm{m}$ can be seen in Table 3. Skin irritation test results in rabbits gave a primary irritation index of 0 (Table 4). Average results for the eye irritation test on CAM were 0 in the negative control; 7.97 for the positive control; and the average yield was 3.82 (Table 5).

\section{DISCUSSION}

EGCG contains a chromophore characterized by the presence of a conjugated double bond, which is responsible absorb the light and can

Table 3: Average globule diameter at varying temperatures at weeks 0 and 8

\begin{tabular}{lll}
\hline Storage temperature & \multicolumn{2}{l}{ Average globule diameter $(\boldsymbol{\mu m})$} \\
\cline { 2 - 3 } & $\mathbf{0}$ week & $\mathbf{8}^{\text {th }}$ week \\
\hline Room temperature $\left(25 \pm 2^{\circ} \mathrm{C}\right)$ & $3.135 \pm 0.56$ & $4.622 \pm 0.72$ \\
Low temperature $\left(4 \pm 2^{\circ} \mathrm{C}\right)$ & $3.135 \pm 0.56$ & $3.05 \pm 0.46$ \\
High temperature $\left(40 \pm 2^{\circ} \mathrm{C}\right)$ & $3.135 \pm 0.56$ & $4.608 \pm 0.52$ \\
\hline
\end{tabular}

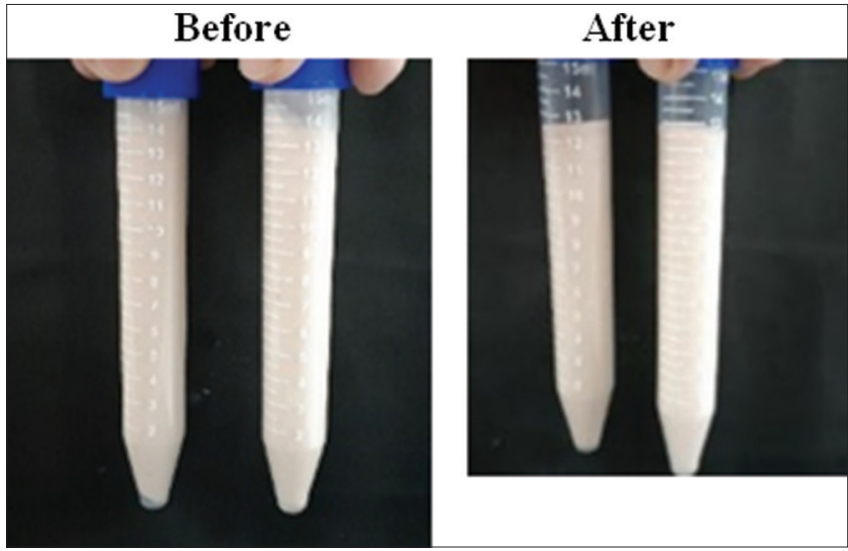

Fig. 5: Before and after mechanical test results

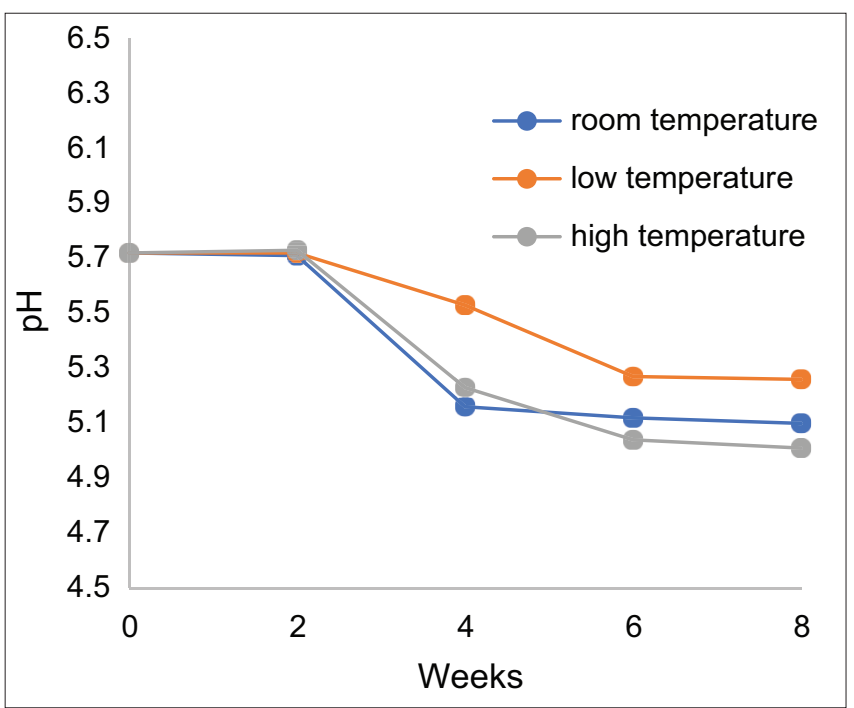

Fig. 6: pH changes at 8 weeks at varying temperatures 
Table 4: Skin irritation test results

\begin{tabular}{|c|c|c|c|c|c|c|c|c|c|c|c|c|c|c|}
\hline \multirow[t]{3}{*}{ Group } & \multirow[t]{3}{*}{ Hour } & \multicolumn{4}{|c|}{ Rabbit 1} & \multicolumn{4}{|c|}{ Rabbit 2} & \multicolumn{4}{|c|}{ Rabbit 3} & \multirow[t]{3}{*}{ PII } \\
\hline & & \multicolumn{2}{|c|}{ Left } & \multicolumn{2}{|c|}{ Right } & \multicolumn{2}{|c|}{ Left } & \multicolumn{2}{|c|}{ Right } & \multicolumn{2}{|c|}{ Left } & \multicolumn{2}{|c|}{ Right } & \\
\hline & & $\mathbf{E}$ & $\mathbf{U}$ & $\mathbf{E}$ & $\mathbf{U}$ & $\mathbf{E}$ & $\mathbf{U}$ & $\mathbf{E}$ & $\mathbf{U}$ & $\mathbf{E}$ & $\mathbf{U}$ & $\mathbf{E}$ & $\mathbf{U}$ & \\
\hline \multirow{3}{*}{ Sample (foundation lotion EGCG) } & 24 & 0 & 0 & 0 & 0 & 0 & 0 & 0 & 0 & 0 & 0 & 0 & 0 & 0.0 \\
\hline & 48 & 0 & 0 & 0 & 0 & 0 & 0 & 0 & 0 & 0 & 0 & 0 & 0 & \\
\hline & 72 & 0 & 0 & 0 & 0 & 0 & 0 & 0 & 0 & 0 & 0 & 0 & 0 & \\
\hline \multirow[t]{3}{*}{ Control (base) } & 24 & 0 & 0 & 0 & 0 & 0 & 0 & 0 & 0 & 0 & 0 & 0 & 0 & \\
\hline & 48 & 0 & 0 & 0 & 0 & 0 & 0 & 0 & 0 & 0 & 0 & 0 & 0 & \\
\hline & 72 & 0 & 0 & 0 & 0 & 0 & 0 & 0 & 0 & 0 & 0 & 0 & 0 & \\
\hline
\end{tabular}

E: Erythema, U: Edema; PII: Primary irritation index, EGCG: Epigallocatechin gallate

Table 5: Irritation score values on CAM following test product use

\begin{tabular}{llllll}
\hline \multirow{2}{*}{ Group } & \multicolumn{3}{l}{ Irritation score } & & \\
\cline { 2 - 6 } & CAM 1 & CAM 2 & CAM 3 & CAM 4 & Average \\
\hline Negative control & 0.0 & 0.0 & 0.0 & 0.0 & 0.0 \\
Positive control & 10.67 & 5.00 & 5.00 & 11.28 & 7.97 \\
EGCG foundation & 3.80 & 3.82 & 3.86 & 3.80 & 3.82 \\
lotion & & & & & \\
\hline
\end{tabular}

EGCG: Epigallocatechin gallate, CAM: Chorioallantois method

absorb UV light - especially UV-B light (UVB) - also prevent the related adverse effects on the skin [11]. In a previous study, the SPF value of $200 \mu \mathrm{g} / \mathrm{mL}$ green tea extract containing 50\% EGCG was $14.29[12,13]$. Based on the initial calculation, $250 \mu \mathrm{g} / \mathrm{mL}$ EGCG was obtained to produce an SPF value of $\sim 30$; however, the resulting SPF was $18.88 \pm 0.42$ thus the tested concentration was increased for about 1.6 times up to $400 \mu \mathrm{g} / \mathrm{mL}$. The SPF value of EGCG at a concentration of $400 \mu \mathrm{g} / \mathrm{mL}$ was $31.02 \pm 0.72$. This value indicates that the photoprotection activity of $400 \mu \mathrm{g} / \mathrm{mL}$ EGCG reached ultra-protection (SPF >15) [6]. Topical application of EGCG before exposure to UVB radiation could also reduce UVB-induced erythema and sunburn. Thus, when EGCG was applied topically, it elicited a photoprotective effect [14]. At higher SPF observed absorbance was also high [15]. SPF value of the EGCG foundation was higher result than those of EGCG active ingredients.There were several factors that may have influenced the determination of SPF values, such as the emulsion, the effect, and interaction of diluents such as esters, emollients, and emulsifiers used in the formulation as well as $\mathrm{pH}$ and viscosity $[6,16]$.

The $\mathrm{pH}$ of the preparation should fall within the range of skin $\mathrm{pH}$ at 4.5-6.5. A lotion that is too alkaline can cause the skin to become scaly, while increased acidity could cause skin irritation. The foundation $\mathrm{pH}$ was 5.72 , which was still within the acceptable range. The lotion exhibited plastic flow that only flowed when shear stress exceeded the yield value, as well as thixotropic flow indicating that structural breakdown was not immediately reformed if the pressure was removed or reduced [17]. The thixotropic flow properties were expected within pharmaceutical preparations, which have high consistency in containers but can be cast and dispersed easily.

The force effect provided by centrifugation for $5 \mathrm{~h}$ at $3800 \mathrm{rpm}$ was considered equivalent to the gravitational force that the lotion would undergo for 1 year of storage in accordance with Stokes' Law. Discoloration at 8 weeks could be caused by high temperatures, thereby the polyphenols more visible due to oxidation processes as characterized by a brownish color $[18,19]$. The foundation at all temperatures tested indicated no odor change and remained homogeneous for up to 8 weeks. Decrease in $\mathrm{pH}$ was due to the presence of ingredients capable of releasing hydrogen ions such as stearic acid, which can increase acidity [18].

Temperature increases can affect stability $[17,20]$. Molecular movement increases with rising temperature so that water globule and oil phases tend to enter the same phase. There was no change in flow properties during storage, but the viscosity value increased to $8600 \mathrm{cps}$. Increased viscosity occurs due to shear stress of stirring during the preparation process. Shear pressure can change the polymer structure of the base to become slightly tenuous; thus, the preparations become more dilute [17]. Following storage, the polymer structure will return to its prior state and the preparations will become more viscous.

This research was declared feasible for performing a test treatment on rabbits and was approved through Ethical Assessment by the Health Research Ethics Committee of Faculty of Medicine University of Indonesia (number 0552/UN2.F1/ETIK/2018). Skin irritation tests of the EGCG foundation on rabbit skin did not result in occurrence of edema or erythema with a primer irritation index equal to 0 , indicating that the preparation did not cause skin irritation. ROPT test results also showed that the preparation did not cause any irritation or allergic reactions on human skin and this was supported in that the $\mathrm{pH}$ value still fell within the $\mathrm{pH}$ range of the skin. EGCG topical preparations showed no harmful effects with minor irritation [11]. This indicates that both the foundation and the active ingredient used within the preparation had no effect on skin irritation.

Changes within CAM caused hyperemia and coagulation. The average irritation score value was 3.82 , i.e., "mild irritation." This was probably because the foundation preparation was not isotonic and some ingredients were present that can cause irritation to the eyes such as tween 80 and propylene glycol. Tween 80 is a surfactant nonionic that may dissolve lipids on mucous eye membranes and induce lysis mucous membranes and coagulating proteins. Propylene glycol may cause irritation on contact with the eyes, resulting in minor injuries and a stinging sensation $[10,21]$.

\section{CONCLUSION}

The EGCG foundation lotion generated here was physically stable, had an attractive appearance, and did not irritate the skin thus was safe to use. Formulation of such foundation lotion using 0.4\% EGCG can effectively counteract UVR as it had an SPF value of $\sim 30$ (i.e., 33.19 \pm 0.59 ). The use of EGCG as a sunscreen in foundation cosmetics could be effective and safe compared to broad-spectrum physical and chemical sunscreens also could replace the imported cosmetics that currently dominate the cosmetics market.

\section{CONFLICTS OF INTEREST}

All authors have none to declare.

\section{REFERENCES}

1. Li YH, Wu Y, Wei HC, Xu YY, Jia LL, Chen J, et al. Protective effects of green tea extracts on photoaging and photommunosuppression. Skin Res Technol 2009;15:338-45.

2. Avadhani KS, Manikkath J, Tiwari M, Chandrasekhar M, Godavarthi A, Vidya SM, et al. Skin delivery of epigallocatechin-3-gallate (EGCG) and hyaluronic acid loaded nano-transfersomes for antioxidant and anti-aging effects in UV radiation induced skin damage. Drug Deliv 2017;24:61-74. 
3. Nohynek GJ, Schaefer H. Benefit and risk of organic ultraviolet filters. Regul Toxicol Pharmacol 2001;33:285-99.

4. Wolf R, Wolf D, Morganti P, Ruocco V. Sunscreens. J. Clinic Dermatol 2001;19:452-9.

5. Deep KC, Saraf S. Photochemoprotective activity of alcoholic extract of Camellia sinensis. Int J Pharmacol 2011;3:400-4.

6. Dutra EA, Oliveira DA, Kedor H, Santoro MI. Determination of sun protection factor (SPF) of sunscreens by ultraviolet spectrophotometry. Braz J Pharm Sci 2004;3:381-5.

7. Duma N. Learn about the stability and irritation effects of foundation lotion formulated with oleum cocoa substitution. Ind Hasil Perkebunan 2014:1:9-17.

8. Scalia S, Marchetti N, Bianchi A. Comparative evaluation of different co-antioxidants on the photochemical- and functional-stability of epigallocatechin-3-gallate in topical creams exposed to simulated sunlight. Molecules 2013;18:574-87.

9. Interagency Coordinating Committee on the Validations of Alternative Methods. ICCVAM-Recommended Test Method Protocol: Hen's Egg Test - Chorioallantoic Membrane (HET-CAM) Test Method; 2010.

10. Cazedey EC, Carvalho FC, Fiorentino FA, Gremiao MP, Salgado HR. Corosite $^{\circledR}$, BCOP and HET-CAM as alternative methods to animal experimentation. Braz J Pharm Sci 2009;4:759-66.

11. OyetakinWhite $\mathrm{P}$, Tribout $\mathrm{H}$, Baron E. Protective mechanisms of green tea polyphenols in skin. Oxid Med Cell Longev 2012;2012:1-8.

12. Darmawan DD. Formulation of Phytosome Gel Preparation of Green Tea Leaf Extract (Camellia sinensis L. Kuntze) and in vitro Penetration test using Franz Diffusion Cells. Depok: Universitas Indonesia; 2016.

13. Hu C, Kitts DD. Evaluation of antioxidant activity of epigallocatechin gallate in biphasic model systems in vitro. Mol Cell Biochem 2001;218:147-55.
14. Elmets CA, Singh D, Tubesing K, Matsui M, Katiyar S, Mukhtar H. Cutaneous photoprotection from ultraviolet injury by green tea polyphenols. J Am Acad Dermatol 2001;44:425-32.

15. Chou J, Robinson T, Doan H. Rapid comparison of UVB absorption effectiveness of various sunscreens by UV-Vis spectroscopy. J Anal Bioanal Tech 2017;8 Suppl 2:355

16. Imam S, Azhar I, Mahmood ZA. In-vitro evaluation of sun protection factor of a cream formulation prepared from extracts of Musa accuminata (L.), Psidium guava (L.) and Pyrus communis (L.). Asian J Pharm Clin Res 2015;8:234-7.

17. Sinko JP. Martin's Physical Pharmacy and Pharmaceutical Sciences: Physical Chemical and Biopharmaceutical Principles in the Pharmaceutical Sciences. $6^{\text {th }}$ ed. Philadelphia, PA: Lippincott Williams \& Wilkins; 2011

18. Vayalil PK, Elmets CA, Katiyar SK. Treatment of green tea polyphenols in hydrophilic cream prevents UVB-induced oxidation of lipids and proteins, depletion of antioxidant enzymes and phosphorylation of MAPK proteins in SKH-1 hairless mouse skin. Carcinogenesis 2003;24:927-36.

19. Widyaningrum N, Fudholi A, Sudarsono SS, Setyowati E. Stability of epigallocatechin gallate (EGCG) from green tea (Camellia sinensis) and its antibacterial activity against Staphylococcus epidermidis ATCC 35984 and Propionibacterium acnes ATCC 6919. Asian J Biol Sci 2015;2:93-101.

20. Djajadisastra J.Cosmetic Stability. Jakarta: Presented in Indonesian Cosmetic Association (HIKI); 2004.

21. Jufri M, Amelia L, Munim A. Hair growth activity and safety test of ethosomal gel ethyl acetate fraction of nothopanax leaves (Nothopanax scutellarium merr.). Asian J Pharm Clin Res 2017;10:134-8. 